MATEC Web of Conferences 19,01030 (2014)

DOI: $10.1051 /$ matecconf/ 20141901030

(C) Owned by the authors, published by EDP Sciences, 2014

\title{
Energy efficiency of electric pulse installation based on a high-current plasma accelerator
}

\author{
I.I. Shanenkov, A.Ya. Pak, A.A. Sivkov, Yu.L. Shanenkova \\ National Research Tomsk Polytechnic University, 634050 Tomsk, Russia
}

\begin{abstract}
The energy efficiency of electric pulse installation based on a high-current plasma accelerator was investigated. A series of experiments with different central electrodes was carried out. The system based on carbon electrodes has a greater value of the charge energy conversion into the energy of arc discharge and the less discharge current level in comparison with other electrode systems. The power consumption value for producing 1 gram of powdered product was estimated and it was found this value is comparable to the work of the LED light bulb for 1 hour.
\end{abstract}

\section{Introduction}

A number of materials with unique properties, that make them suitable for renewable energy in order to produce hydrogen from water, are well-known. In particular, platinum and other precious metals, rare metals are widely-used in this sphere of power engineering. In recent years, there are reports about the high photocatalytic activity of ultrafine tungsten carbides and carbon nitrides [1-4]. These materials can conceivably replace the precious and rare metals of "platinum group" in the catalyst systems.

The electro discharge technology based on plasma acceleration processes can be used to obtain tungsten carbides and carbon nitrides in the ultrafine form [5,6]. However, now this technology is in the stage of research work, this is why the difficult task is the assessment of its cost-effectiveness. In this case, it is necessary to assess the electric energy consumption and its cost per mass unit of the resulting material.

To investigate the ways of the possible improvement of the energy efficiency of the installation based on pulse coaxial plasma accelerator, the series of experiments with constant parameters of the pulsed power supply and different materials of the electrode system has been carried out.

\section{Experimental}

Experiments were carried out in accordance with the previously-described way [5]. A sketch-map of the experimental setup is shown in Figure 1. The coaxial magneto plasma accelerator (CMPA) was installed by its barrel in a sealed chamber. The power supply of CMPA was provided from the capacitive energy storage. In all experiments, the energy parameters of the energy storage were as follows: capacitance $\mathrm{C}=6.0 \mathrm{mF}$, charging voltage $\mathrm{U}=3.0 \mathrm{kV}$. Thus, the accumulated energy was 27 $\mathrm{kJ}$. In all cases, the graphite was used as the material of the accelerating channel (negative potential electrode). The central electrode of the accelerator was made of brass and completed with tips, made from different materials. In experiments three types of tips of CMPA central electrode (positive 


\section{MATEC Web of Conferences}

potential) were used. There were metallic tungsten, titanium metal and graphite. All of these electrodes were used to obtain different compositions of ultrafine materials based on tungsten, boron, silicon, titanium, carbon [5, 7-10]. The generated plasma structure depended on the material of the acceleration channel, the material of the central electrode tip, the material of the electrical bridge between the electrodes of the accelerator, the gaseous atmosphere of the reactor. Before the working cycle the chamber was filled with argon under normal conditions. In the plasma formation zone various mixtures were loaded: tungsten $(\mathrm{W})$ and carbon $(\mathrm{C})$, titanium $(\mathrm{Ti})$ and carbon $(\mathrm{C})$, pure carbon $(\mathrm{C})$ in equal amounts (about $1 \mathrm{~g}$ ) and the equal mixing ratio by weight (1:1).

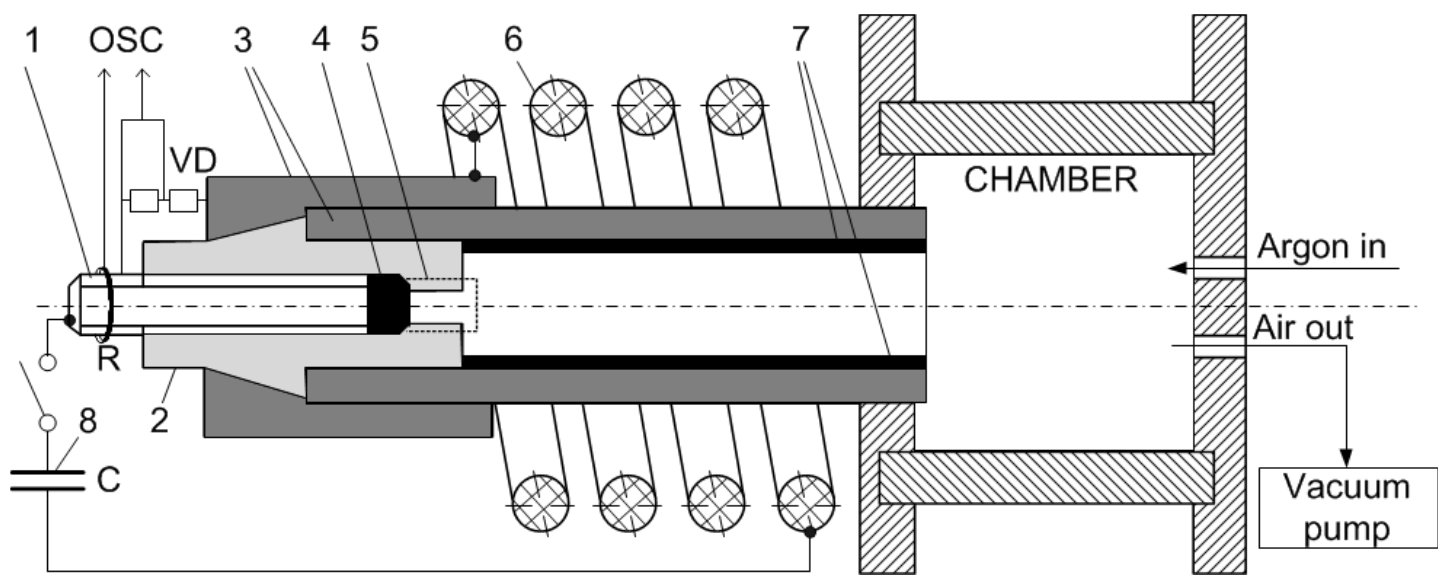

Figure 1. Sketch-map of the system. 1 - brass central electrode; 2 - insulator; 3 - metal case; 4 - tips made of different materials; 5 - plasma formation zone; 6 - inductor; 7 - graphite accelerating channel; 8 - capacitive energy storage; R - Rogowski coil; VD - voltage divider; OSC - Oscilloscope

Working parameters of the accelerator in the operation mode were recorded by oscilloscopes (OSC) using resistive voltage dividers (VD) and Rogowski transformers (R). Typical oscillograms are shown in Figure 2. The curves of current and voltage were multiplied to obtain the curve of power. By integrating this curve it is possible to calculate the electrical energy, released during the working cycle.
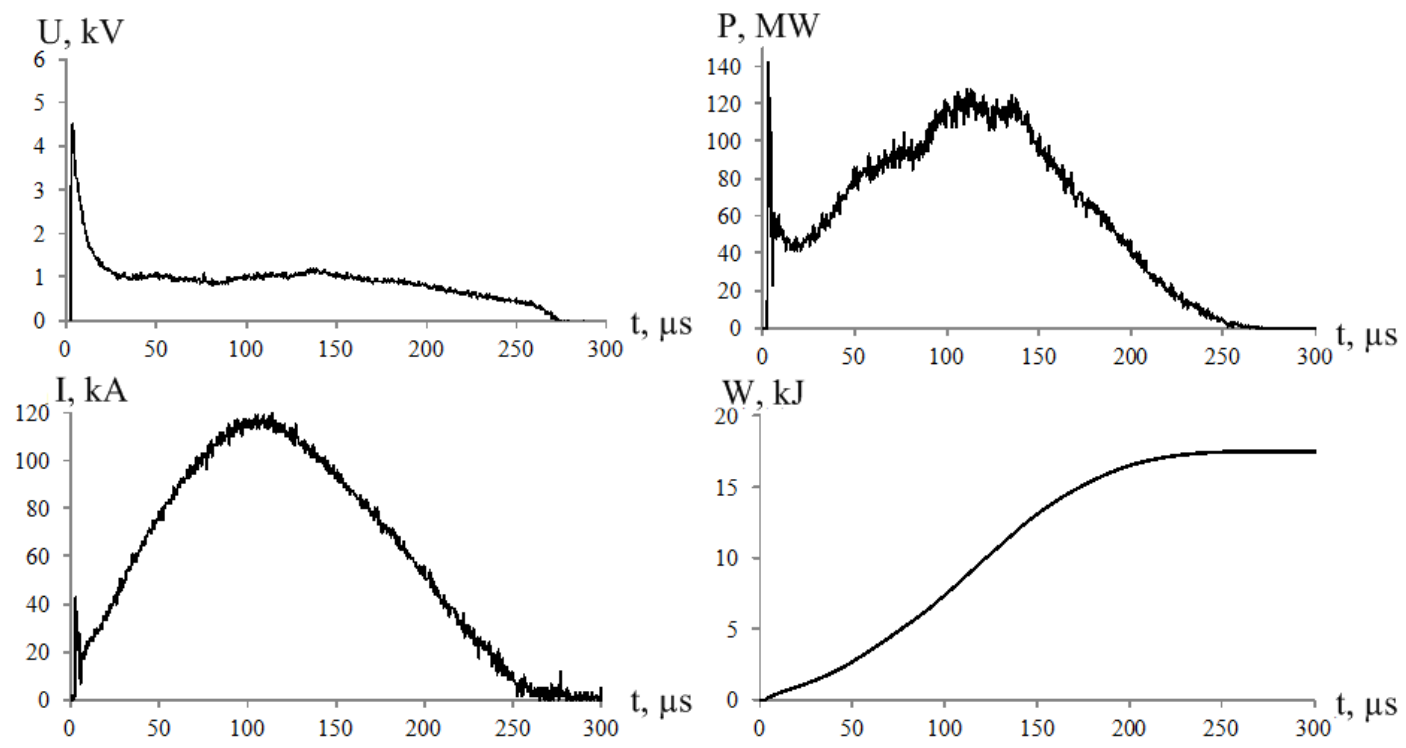

Figure 2. Typical oscillograms of voltage, current and calculated curves of power and energy 


\section{Results and Discussion}

The main initial data of experiments and the energy parameters of the operating cycle averaged over a series of experiments are shown in Table 1. Considering the first group of experiments (Table 1, items 1 and 2), connected with the generation of tungsten-carbon electrical discharge plasma flow, it is seen that the power amplitude and the amount of released energy is more when the graphite central electrode is used for. Moreover, the levels of current and voltage at the same time are approximately equal, but in the case of the use of the tungsten electrode, there is some non simultaneity in the achievement of the amplitude values of current and voltage curves. As a result, the ratio of the energy of the arc discharge in the accelerator, referred to the energy of the supply source, is significantly higher when using the graphite tip of the central electrode.

For the second group of experiments ( 3 and 4, Table 1), connected with the generation of titaniumcarbon electric discharge plasma, it is similarly seen the increasing of the average power, released energy and, correspondingly, its proportion related to the supplied energy in the case of using the graphite tip of the central electrode (item 4 of Table 1).

Also a series of experiments on the accelerator work with both positive and negative potential electrodes made of graphite (Table 1, item 5) has been carried out. In this case, the accelerator generates the carbon plasma flow and it is seen the highest amplitude values of power and input energy from the considered ones.

Thus the best results from the point of efficiency of the supplied energy conversion to the energy of arc discharge are provided with using of accelerator based on the graphite electrode system working in a mode of generation carbon plasma without admixtures of other chemical elements, in particular tungsten and titanium. Moreover, the increasing of power occurs due to increasing of the arc voltage, that is a positive moment in view of the destructive effect of electrodynamic processes on the system at high current levels. Increasing the voltage can be caused by an increase in the plasma temperature and pressure in the accelerating channel if the discharge plasma contains only carbon. According to the known data $[11,12]$ the temperature of carbon plasma at considered levels of current can reach about $10.000 \mathrm{~K}$.

Table 1. Main parameters of experiment series

\begin{tabular}{|l|l|l|l|l|l|l|l|l|l|}
\hline № & $\begin{array}{l}\text { Tip } \\
\text { material }\end{array}$ & $\begin{array}{l}\text { Plasma } \\
\text { structure }\end{array}$ & $\begin{array}{l}\mathrm{U}, \\
\mathrm{kV}\end{array}$ & $\begin{array}{l}\mathrm{I}, \\
\mathrm{kA}\end{array}$ & $\begin{array}{l}\mathrm{P}, \\
\mathrm{MW}\end{array}$ & $\begin{array}{l}\mathrm{t}_{\mathrm{p}}, \\
\mu \mathrm{s}\end{array}$ & $\begin{array}{l}\mathrm{E}, \\
\mathrm{kJ}\end{array}$ & $\begin{array}{l}\mathrm{P}_{\mathrm{av}}, \\
\mathrm{MW}\end{array}$ & $\begin{array}{l}\mathrm{E} / \mathrm{Ec}, \\
\%\end{array}$ \\
\hline 1 & $\mathrm{~W}$ & $\mathrm{~W}+\mathrm{C}$ & 1.30 & 119 & 109 & 287 & 16.0 & 55.7 & 59.3 \\
\hline 2 & $\mathrm{C}$ & $\mathrm{W}+\mathrm{C}$ & 1.26 & 117 & 153 & 270 & 19.0 & 78.8 & 70.4 \\
\hline 3 & $\mathrm{Ti}$ & $\mathrm{Ti}+\mathrm{C}$ & 0.88 & 133 & 133 & 245 & 17.7 & 72.2 & 65.6 \\
\hline 4 & $\mathrm{C}$ & $\mathrm{Ti}+\mathrm{C}$ & 1.10 & 119 & 137 & 241 & 19.2 & 79.6 & 71.1 \\
\hline 5 & $\mathrm{C}$ & $\mathrm{C}$ & 1.85 & 114 & 156 & 277 & 19.3 & 69.7 & 71.5 \\
\hline
\end{tabular}

At considered parameters of the power source the plasma accelerator provides obtaining in one working cycle up to $1 \mathrm{~g}$ of powdered products such as tungsten carbide [5], boron [7], the material close to the carbon nitride [6]. Thus energy costs related to obtaining of a unit mass of product (Ec/m) can be estimated. So in all cases, this value was about $27 \mathrm{~kJ} / \mathrm{g}(7.56 \mathrm{Wh} / \mathrm{g})$ at the maximum efficiency of the power source energy transfer to the energy of the arc discharge $71.5 \%$. The derived value indicates that electricity costs of the pulsed power source per 1 gram of the product are comparable to costs during the work of one LED bulb for 1 hour. The low energy consumption is one of the advantages of the being in develop technology, based on the high-current pulsed plasma accelerator, for production of ultrafine materials.

\section{Conclusion}

The series of experiments was carried out to investigate the energy efficiency of electric pulse installation based on a high-current coaxial magnetoplasma accelerator. The maximum efficiency of 


\section{MATEC Web of Conferences}

the use of pulsed power source exceeds $70 \%$ when the plasma accelerator works with graphite electrodes. At the same time typical parameters of power source, permitting to obtain different materials using the considered accelerator, allow to estimate the power consumption for producing $1 \mathrm{~g}$ of product. This value is small enough and was $27 \mathrm{~kJ} / \mathrm{g}(7.56 \mathrm{Wh} / \mathrm{g})$ and comparable to the work of the LED light bulb for 1 hour. The low power consumption and the high efficiency are advantages of the being in develop pulsed electric technology.

\section{References}

1. Y. Tian, B. Chang, J. Fu, B. Zhou, J. Liu, F. Xi, X. Dong, J. Solid State Chem. 212, 1 (2014)

2. J. Kim, J.-H. Jang, Y.-H. Lee, Y.-U. Kwon, J. Power. Sour. 193, 441 (2009)

3. L. Song, Sh. Zhang, X. Wu, Q. Wei, Chem. Eng. J. 184, 256 (2012)

4. X. Xu, G. Liu, Ch. Randorn, J.T.S. Irvine, Inter. J. of hydrogen energy 36, 13501 (2011)

5. A. Pak, A. Sivkov, I. Shanenkov, I. Rahmatullin, K. Shatrova, Int. J. Refract. Met. Hard Mater. 48, 51 (2015)

6. A. Sivkov, A. Pak, I. Shanenkov, Y. Kolganova, I. Prosvirin, Adv. Mater. Res. 880, 36 (2014)

7. A. Sivkov, A. Pak, J. Superhard Mater. 1, 21 (2010)

8. A.A. Sivkov, A.Y. Pak, D.S. Nikitin, I.A. Rakhmatullin, I.I. Shanenkov, Nanotechnologies in Russia 8, 489 (2013)

9. A.A. Sivkov, D.Yu. Gerasimov, A.S. Saigash, A.A. Evdokimov, Russ. Phys. J. 54, 1160 (2012)

10. A.A. Sivkov, D.S. Nikitin, A.Ya. Pak, I.A. Rakhmatullin, Tech. Phys. Lett. 39, 105 (2013)

11. J. Puric, I.P. Dojcinovic, V.M. Astashynski, M.M. Kuraica, B.M. Obradovic, Plasma Sources Sci. Technol. 13, 74 (2004)

12. S.V. Bobashev, B.G. Zhukov, R.A. Kurakin, S.A. Ponyaev, B.I. Reznikov, S.I. Rozov, J. Tech. Phys. 55, 1754 (2010) 